\title{
Relationship Between Microstructures and Microhardness in High-Speed Friction Stir Welding of AA6005A-T6 Aluminum Hollow Extrusions
}

\author{
Xiang-Qian Liu ${ }^{1} \cdot$ Hui-Jie Liu ${ }^{2} \cdot$ Yan Yu ${ }^{1}$ \\ Received: 2 April 2019 / Revised: 4 August 2019 / Published online: 4 December 2019 \\ (c) The Chinese Society for Metals (CSM) and Springer-Verlag GmbH Germany, part of Springer Nature 2019
}

\begin{abstract}
AA6005A-T6 aluminum hollow extrusions were friction stir welded at a fixed high welding speed of $2000 \mathrm{~mm} / \mathrm{min}$ and various rotation speeds. The results showed that the heat-affected zone (HAZ) retained the similar grain structure as the base material except some grain coarsening, and the density of dislocations and $\beta^{\prime}$ precipitates were almost unchanged, indicating that the high welding speed inhibited the coarsening and dissolution of $\beta^{\prime \prime}$ precipitates via fast cooling rate. The thermo-mechanically affected zone (TMAZ) was characterized by elongated and rotated grains, in which a low density of $\beta^{\prime}$ precipitates and the highest density of dislocations were observed. The highest heat input and severest plastic deformation occurring in the nugget zone (NZ) resulted in the occurrence of dynamic recrystallization and a high density of dislocations. Hence, all the $\beta^{\prime \prime}$ precipitates and most of the $\beta^{\prime}$ precipitates dissolved into the matrix, and a few $\beta^{\prime}$ precipitates were transformed into $\beta$ precipitates. The microhardness was controlled by the precipitation and solution strengthening in the HAZ, by the dislocation and precipitation strengthening in the TMAZ, and by the fine-grain and dislocation strengthening in the NZ. With the increase in rotation speed, the peak and the lowest microhardness value increased monotonously.
\end{abstract}

Keywords Aluminum hollow extrusions · High-speed friction stir welding · Grain structure · Dislocation and precipitates . Microhardness distribution

\section{Introduction}

The aluminum hollow extrusions have been extensively used in high-speed train manufacturing industry due to their high rigidity, favorable strength/weigh ratio, good flatness, and excellent corrosion resistance [1]. They can replace the functions of conventional welding components including beams and plates, and thus can simplify the welding procedures and reduce the vehicle's weight [2]. Typically, the aluminum hollow extrusions are welded to form large-scale components. Friction stir welding (FSW) can produce low-distortion, high-quality, and low-cost joints, which makes it a promising

Available online at http://link.springer.com/journal/40195

Xiang-Qian Liu

liuxqhit@163.com

1 Luoyang Ship Material Research Institute, Luoyang 471023, China

2 State Key Laboratory of Advanced Welding and Joining, Harbin Institute of Technology, Harbin 150001, China method for joining the aluminum hollow extrusions [3]. The heat input and/or plastic deformation during FSW is sufficient to cause undesired microstructural evolution, thereby leading to localized softening in microhardness.

To improve the microstructural evolution and microhardness, controlling the heat input into the workpiece is an effective way. Some modified welding methods including underwater FSW (UFSW) and stationary shoulder FSW (SSFSW) are developed in recent years [4, 5]. The UFSW controls the thermal cycles in the thermo-mechanically affected zone (TMAZ) and heat-affected zone (HAZ) by water cooling, inhibits the coarsening and dissolution of precipitates, and consequently improves the microhardness in these two zones. However, the UFSW presents significant limitations for the joining of large-scale aluminum components such as train body. The SSFSW lowers the heat input as the non-rotational shoulder contributes little to the heat generation, and weakens the precipitate coarsening and dissolution. But, the welding speed is seriously limited by the low heat input, which has a direct negative influence on the welding efficiency. 
The heat input is directly proportional to the ratio of rotation speed to welding speed $[6,7]$, and increasing the welding speed has been proved a helpful method for improving the microstructures and microhardness. Dong et al. [8] found that the $\beta^{\prime \prime}$ precipitates in the base material (BM) completely dissolved into the nugget zone (NZ). The transformation of $\beta^{\prime \prime} \rightarrow \beta^{\prime}$ and the precipitation of $Q^{\prime}$ occurred in the HAZ close to the TMAZ, and the residual $\beta^{\prime \prime}$ precipitates can be found in the HAZ close to the BM due to lower heat input and cooling rate. Increasing the welding speed could restrain the dissolution of $Q^{\prime}$ and $\beta^{\prime \prime}$ precipitates, and the microhardness increased monotonously. Similar conclusions were obtained in the investigation of Zhang et al. [9]. They reported that increasing the welding speed inhibited the coarsening of $\mathrm{Al}_{2} \mathrm{Cu}$ precipitates in the low-hardness zone and increased the microhardness. In short, a lot of efforts were made to investigate the microstructural evolution and microhardness, while the majority of welding speeds used in the experiments were less than $1000 \mathrm{~mm} / \mathrm{min}$ [10-12]. The present authors $[13,14]$ conducted high-speed FSW (HSFSW) of AA6005A-T6 aluminum alloy, and studied the microstructural characteristics and mechanical properties. However, the relationship between microstructures and microhardness of HSFSW joint has not been reported yet.

In the present work, the AA6005A-T6 aluminum hollow extrusions were friction stir welded at a fixed high welding speed of $2000 \mathrm{~mm} / \mathrm{min}$ and various rotation speeds, with the aim of highlighting the correlation between microstructures and microhardness of HSFSW joint. This work was focused on the grain structure, dislocation, precipitates, and microhardness.

\section{Experimental}

AA6005A-T6 aluminum hollow extrusions which were $300 \mathrm{~mm}$ long with $4 \mathrm{~mm}$ butting depth were used as the BM. The chemical compositions in weight percent were 0.6 $\mathrm{Mg}, 0.7 \mathrm{Si}, 0.5 \mathrm{Mn}, 0.35 \mathrm{Fe}, 0.3 \mathrm{Cu}, 0.3 \mathrm{Cr}, 0.2 \mathrm{Zn}, 0.1 \mathrm{Ti}$, and balance Al. The workpiece was firstly clamped on the workbench, and then butt welds were made along the longitudinal direction which was parallel to the extrusion direction. The ESAB SuperStir ${ }^{\mathrm{TM}}$ FSW machine was used for all the welding experiments. The FSW tool comprised of a flat shoulder with a diameter of $20 \mathrm{~mm}$ and a conical pin with a median diameter of $7.4 \mathrm{~mm}$ and a length of $3.8 \mathrm{~mm}$. The tilt angle of tool was kept constantly at $1.5^{\circ}$, and the axial force was set as $17 \mathrm{kN}$. The welding speed was fixed at a high value of $2000 \mathrm{~mm} / \mathrm{min}$, and the rotation speed varied from 2000 to $3000 \mathrm{r} / \mathrm{min}$.

The thermal cycles were measured at three locations that were $12 \mathrm{~mm}$ (point 1), $15 \mathrm{~mm}$ (point 2), and $18 \mathrm{~mm}$ (point 3) away from the weld center on the advancing side, as illustrated in Fig. 1a. The holes $1 \mathrm{~mm}$ in diameter and $2 \mathrm{~mm}$ in depth were machined, and K-typed thermocouples were fixed in the holes using high-temperature tape. As the tool moved forward at high speed, the time intervals of data acquisition must be small enough to record the transient temperature. The ADAM-4118 thermocouple input module was used in the temperature measuring equipment developed by the authors, and the sampling frequency was $100 \mathrm{~Hz}$. Then a finite element model was established to carry out the temperature simulation, and the predicted thermal cycles were in good agreement with the measured ones, demonstrating that the built thermal model had enough simulation accuracy, as shown in Fig. 1b.

After welding, the joints were cross-sectioned perpendicular to the welding direction for microstructure analyses. The cross sections of the metallographic samples (a)

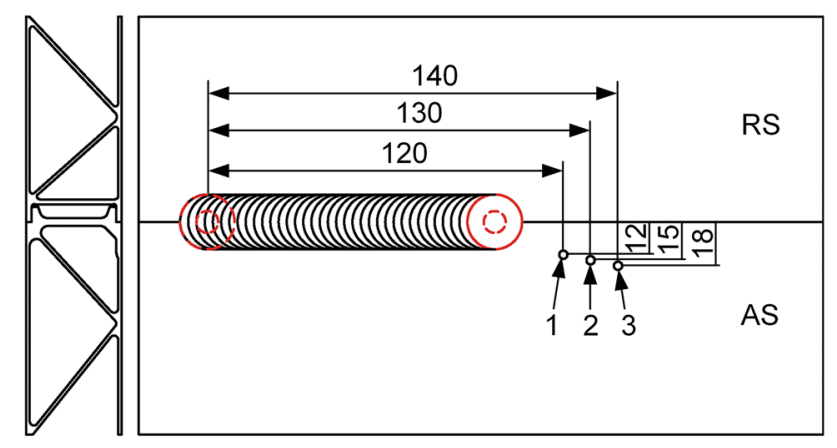

End view

Plan view (b)

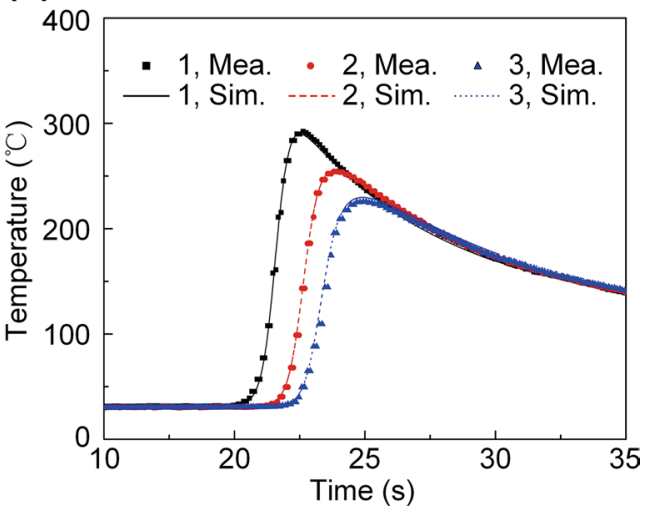

Fig. 1 a Locations of the thermocouples; $\mathbf{b}$ comparison between the measured and predicted thermal cycles at different locations 
were polished using a diamond paste, anodized in the Baker's solution $\left(7.5 \mathrm{ml} \mathrm{HBF}_{4}+75 \mathrm{ml} \mathrm{H}_{2} \mathrm{O}_{2}+217 \mathrm{ml}\right.$ $\mathrm{H}_{2} \mathrm{O}$ ) at $25 \mathrm{~V}$ for $5 \mathrm{~min}$, and observed by digital microscopy (DM, KEYENCE VHX-1000). The precipitates and dislocations in different zones were observed by transmission electron microscopy (TEM, JEM-2100). The samples were machined into foil disks $100 \mu \mathrm{m}$ in thickness and $3 \mathrm{~mm}$ in diameter, and then were thinned by twin-jet electropolishing using a solution of $30 \%$ nitric acid in methanol $\left(18 \mathrm{~V},-35{ }^{\circ} \mathrm{C}\right)$. Microhardness profiles were measured at the mid-thickness ( $2 \mathrm{~mm}$ from the top surface) by a microhardness tester (HVS-1000Z). The spacing between adjacent measuring points was $0.5 \mathrm{~mm}$, and the testing load was $0.98 \mathrm{~N}$ for $10 \mathrm{~s}$.

\section{Results and Discussion}

\subsection{Grain Structure in Each Zone}

During FSW, coincidence of high heat input and severe plastic deformation within the stirred zone results in the occurrence of dynamic recrystallization within the stirred zone and the precipitate dissolution and coarsening within and around the stirred zone [15]. Based on microstructural characterization of grains and precipitates, the joint was divided into BM, HAZ, TMAZ, and NZ (stirred zone), as shown in Fig. 2a.

The grains in the BM were elongated along the extruding direction (Fig. 2b). The HAZ only sustained a low thermal cycle, and the grain structure in the HAZ was similar to thatin the BM except some grain coarsening (Fig. 2c). The TMAZ experienced higher heat input, and the grains were
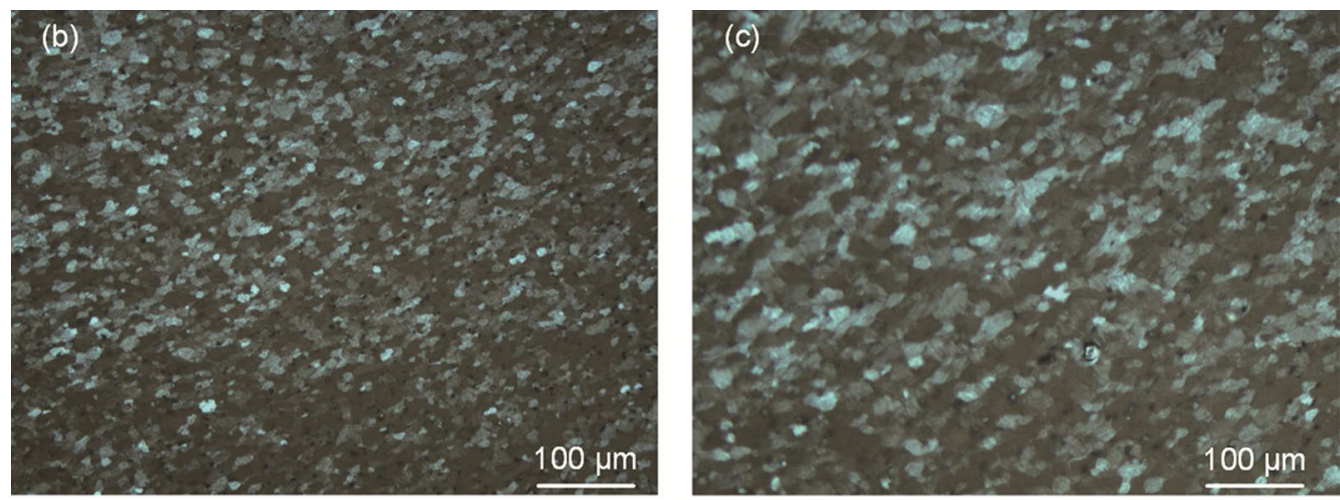

(a)
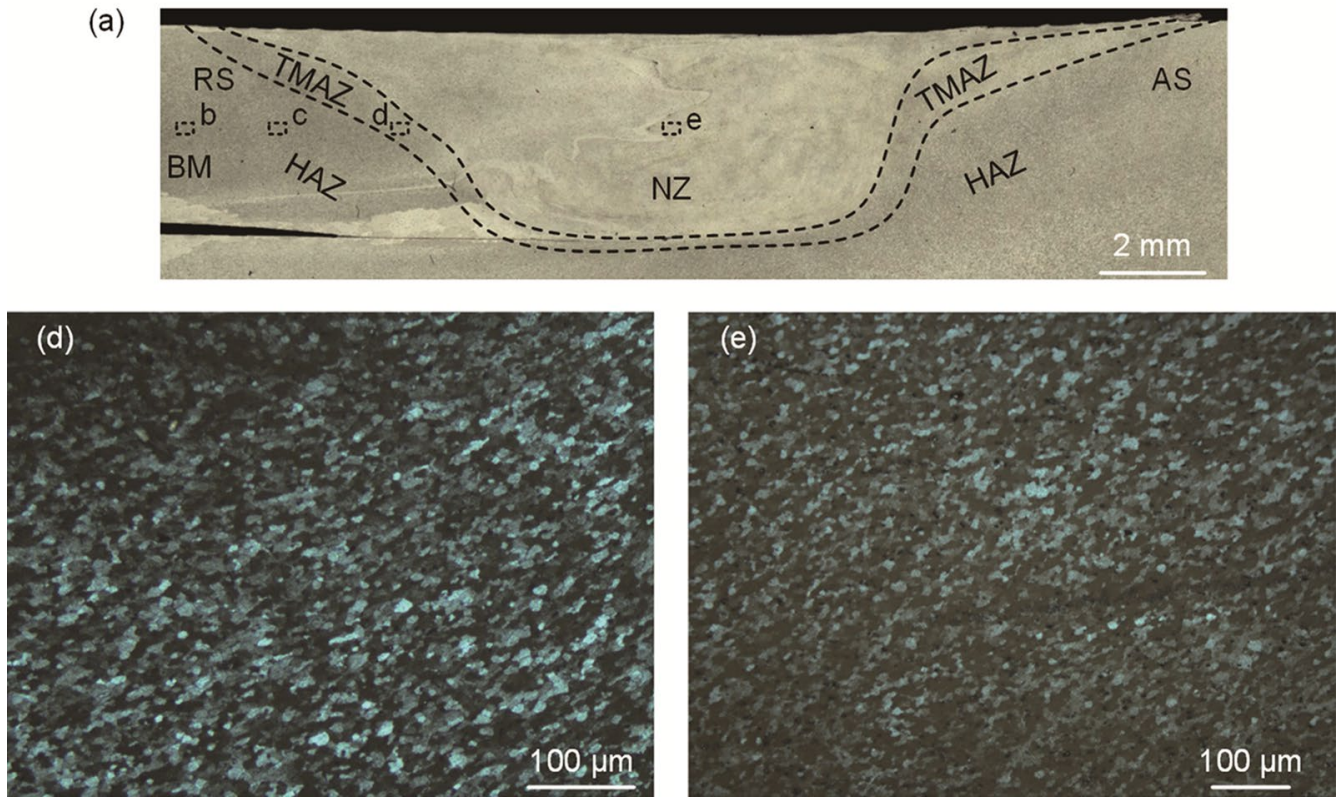

Fig. 2 Optical pictures showing grain structures in different zones: a macrostructure of the weld cross section, b BM, c HAZ, d TMAZ, e NZ (b-e are zones taken from the black boxes in $\mathbf{a})$ 
upward distorted and rotated due to the plastic deformation of the weld material (Fig. 2d). In comparison with the BM, the material in the NZ was directly stirred by the FSW tool, and the high frictional heating and severe plastic deformation led to the highly fine-grained microstructure (Fig. 2e).

\subsection{Microstructures in the BM}

The TEM images showing dislocations and precipitates in the BM are shown in Fig. 3. The BM sustained some mechanical deformation in the extruding process, and a low density of dislocations was introduced into the grains (Fig. 3a). From the TEM images at low magnification, a low density of rod-shaped precipitates (120-210 nm in length, marked with black boxes) and very few plateshaped precipitates (marked with white ellipses) were found (Fig. 3b). When observing along the [001] zone axis at high magnification, it is seen from Fig. $3 c$ that the grains contained a high density of pin-shaped precipitates (20-40 $\mathrm{nm}$ in length and 2-4 $\mathrm{nm}$ in diameter), and they aligned along the three $\langle 100\rangle_{\mathrm{Al}}$ directions.

Previous studies indicated that the needle-shaped precipitate $20-50 \mathrm{~nm}$ in length was $\beta^{\prime \prime}$ precipitate, which was fully coherent with the matrix and the mechanical strength of the $6 \times x x$ series aluminum alloy originated mainly from the $\beta^{\prime \prime}$ precipitates [16]. The rod-shaped precipitate $50-700 \mathrm{~nm}$ in length was $\beta^{\prime}$ precipitate, which was semicoherent with the matrix, and its strengthening effect was weaker than that of $\beta^{\prime \prime}$ [17]. The plate-shaped precipitate was equilibrium phase $\beta$, which was non-coherent with the matrix and made little contribution to the strength of aluminum alloys [18]. Therefore, the grains in the BM were composed of a high density of $\beta^{\prime \prime}$ precipitates and a low density of $\beta^{\prime}$ precipitates. In addition, the precipitatefree zone (PFZ) $150 \pm 20 \mathrm{~nm}$ in length was found along the grain boundaries (Fig. 3d).
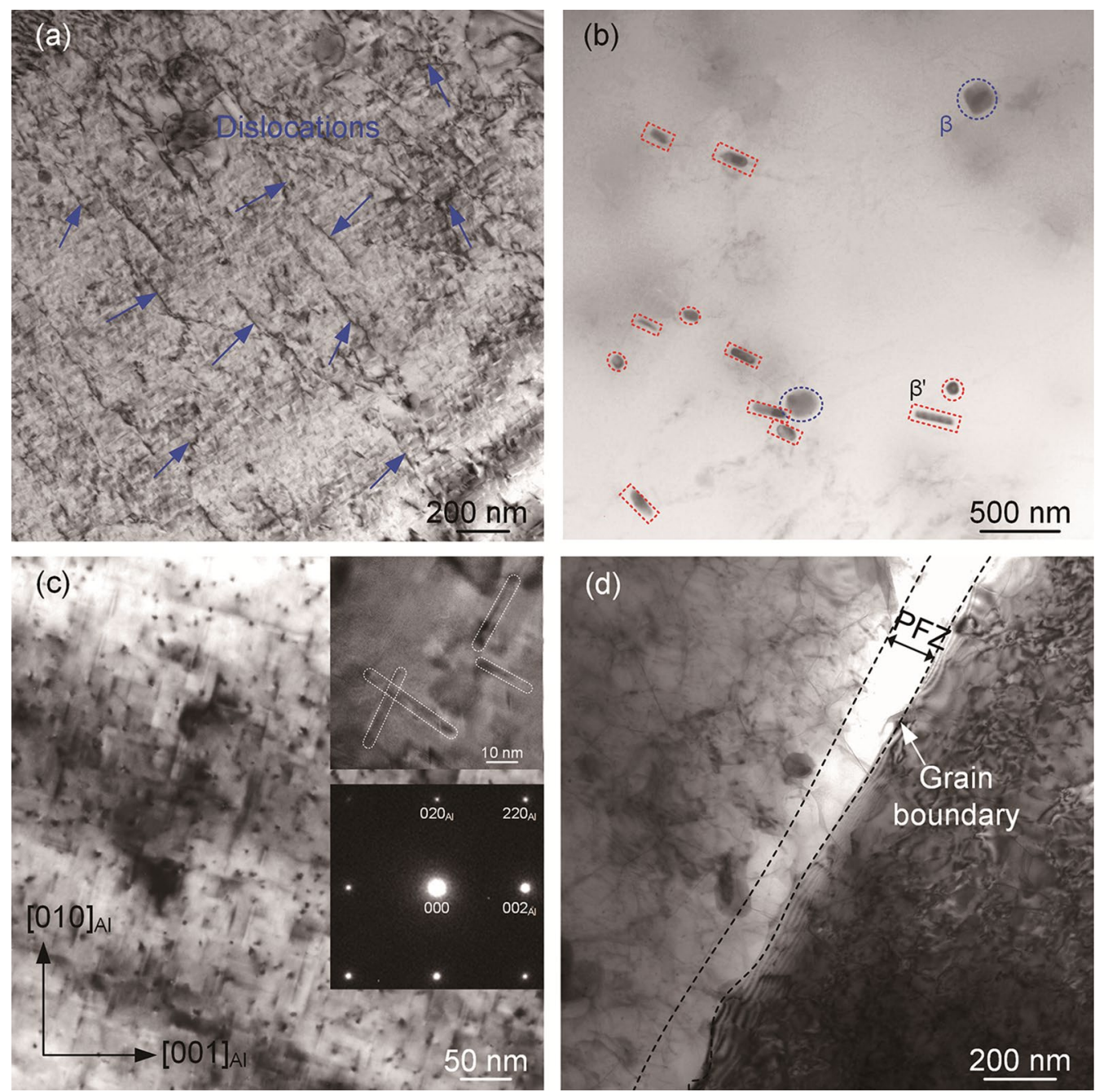

Fig. 3 TEM images showing dislocations and precipitates in the BM: a dislocations, $\mathbf{b} \beta^{\prime}$ and $\beta$ precipitates at low magnification, $\mathbf{c} \beta^{\prime \prime}$ precipitates at high magnification, $\mathbf{d}$ precipitate-free zone 


\subsection{Relationship Between Temperature and Microstructures}

In the NZ, the recrystallized grain size $d_{r}$ can be expressed as [19]

$d_{r}^{2}-d_{0}^{2}=A \cdot \exp (-\Delta E / R T) t$

where $d_{0}$ is the initial recrystallized grain size, $A$ is a constant, $\Delta E$ is the activation energy for grain growth, $R$ is the ideal gas constant, $T$ is the absolute temperature, and $t$ is the time. It is indicated that the recrystallized grain size is mainly affected by the temperature exceeding the grain growth.

A well-accepted precipitation sequence in the $6 \mathrm{xxx}$ series aluminum alloy is: $\mathrm{SSS} \rightarrow \beta^{\prime \prime}\left(\mathrm{Mg}_{5} \mathrm{Si}_{6}\right) \rightarrow \beta^{\prime}\left(\mathrm{Mg}_{9} \mathrm{Si}_{5}\right) \rightarrow \beta$ $\left(\mathrm{Mg}_{2} \mathrm{Si}\right)$ [20, 21]. Many authors [22-24] studied the developed precipitates during continuous heating using differential scanning calorimetry (DSC) and TEM techniques, and the precipitate evolution related to the temperature was concluded as follows: (1) the growth or dissolution of $\beta^{\prime \prime}$ precipitates in the range of $207-250{ }^{\circ} \mathrm{C}$; (2) the transformation from $\beta^{\prime \prime}$ to $\beta^{\prime}$ in the range of $250-317^{\circ} \mathrm{C}$; (3) the dissolution of $\beta^{\prime}$ precipitates from 400 to $480{ }^{\circ} \mathrm{C}$; (4) the dissolution of $\beta$ precipitates at $502^{\circ} \mathrm{C}$.

The evolution of precipitate consisting of $\mathrm{Mg}$ and $\mathrm{Si}$ atoms belonged to the diffusion transformation, and it was realized by the diffusion of thermally activated $\mathrm{Mg}$ and $\mathrm{Si}$ atoms. In the diffusion process, Fick's diffusion law should be obeyed, and the diffusion coefficient $D$ can be given by [25]

$D=D_{0} \cdot \exp (-Q / R T)$

where $D_{0}$ is the diffusion constant, and $Q$ is the diffusion activation energy of solute atoms per mole, including the formation energy of vacancies and the migration energy of solute atoms. The diffusion constants of $\mathrm{Mg}$ and $\mathrm{Si}$ atoms in $\alpha$-Al matrix are $1.24 \times 10^{-4} \mathrm{~m}^{2} / \mathrm{s}$ and $2.08 \times 10^{-4} \mathrm{~m}^{2} / \mathrm{s}$, respectively [26]. The diffusion activation energies of $\mathrm{Mg}$ and $\mathrm{Si}$ atoms in $\alpha$-Al matrix are $131 \mathrm{~kJ} / \mathrm{mol}$ and $124 \mathrm{~kJ} / \mathrm{mol}$, respectively [27]. The thermally induced vacancies can be considered as stable defects, and the equilibrium concentration of vacancies increases with increasing temperature. The value in the BM via heat treatment is very high. This suggested that the diffusion activation energies of solute atoms decreased significantly, and they are mainly dependent on the migration energy. The migration energies of $\mathrm{Mg}$ and $\mathrm{Si}$ atoms in $\alpha-\mathrm{Al}$ matrix are $57.7 \mathrm{~kJ} / \mathrm{mol}$ and $52.7 \mathrm{~kJ} / \mathrm{mol}$, respectively [27]. In the diffusion transformation process, the concentrations of solute atoms remained unchanged, and the grain size $d$ can be seen as the maximum diffusion distance. The complete diffusion time of solute atoms in $\alpha-\mathrm{Al}$ matrix $t_{\mathrm{c}}$ can be simply calculated by [28] $t_{c}=\pi d^{2} / 4 D$

\subsection{Microstructural Evolution in the HAZ}

Figure 4 displays the simulated thermal cycles in each zone of the HSFSW joints welded at different rotation speeds. The cross section of the HSFSW joint was observed by digital microscopy, and the width of the NZ was measured. When the rotation speed was increased from 2000 to $3000 \mathrm{r} / \mathrm{min}$, the width of the NZ was determined to be $8.72 \mathrm{~mm}, 9.40 \mathrm{~mm}$ and $9.52 \mathrm{~mm}$ by the measurement in the metallographic graphics. The width of the TMAZ was hard to be measured accurately, and the value was about $0.5-1.0 \mathrm{~mm}$. Therefore, the point $0 \mathrm{~mm}$ away from the weld center was chosen to represent the NZ, and the points $5 \mathrm{~mm}$ and $8 \mathrm{~mm}$ away from the weld center were chosen to represent the TMAZ and HAZ, respectively. The heating rate and peak temperature $T_{\mathrm{P}}$ increased as the rotation speed increased, and the temperature can reach the peak value in a short time $(\sim 1 \mathrm{~s})$. Meanwhile, there was no obvious difference in the cooling rate. The artificial aging temperature for the 6005 aluminum alloy is $175^{\circ} \mathrm{C}$, and the range of temperature exceeding this value is called the dwelling time at high temperature $t_{\mathrm{D}}$ in this study.

$T_{\mathrm{P}}$ and $t_{\mathrm{D}}$ are two main factors affecting the precipitate evolution, and the detailed data in each zone are given in Fig. 5. The values of $T_{\mathrm{P}}$ in the HAZ, TMAZ, and NZ were in the range of $256-282{ }^{\circ} \mathrm{C}, 401-438{ }^{\circ} \mathrm{C}$, and $473-518^{\circ} \mathrm{C}$, respectively. The values of $t_{\mathrm{D}}$ in the HAZ, TMAZ, and NZ were in the range of 2.4-3.5 s, 3.5-4.6 s, and 3.8-4.9 s, respectively. These thermal characteristics gave rise to different precipitate evolution.

The weakest zone with the minimum microhardness was always located in the HAZ, which had the same density of

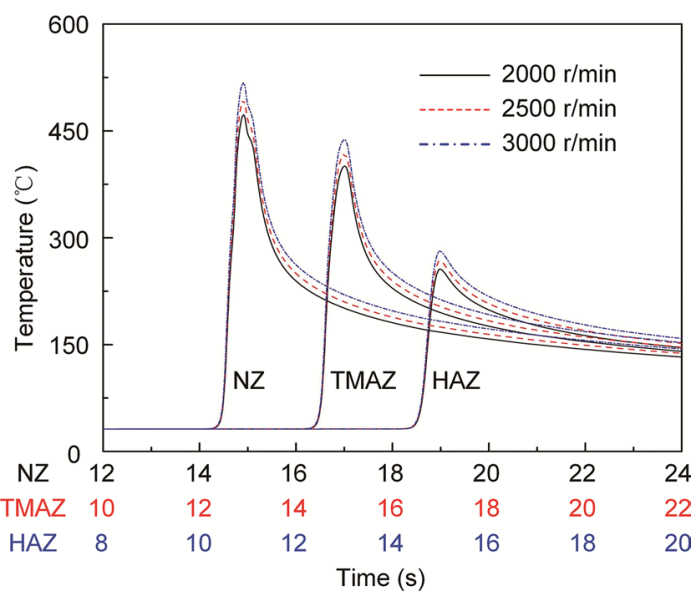

Fig. 4 Welding thermal cycles in different zones obtained at various rotation speeds 


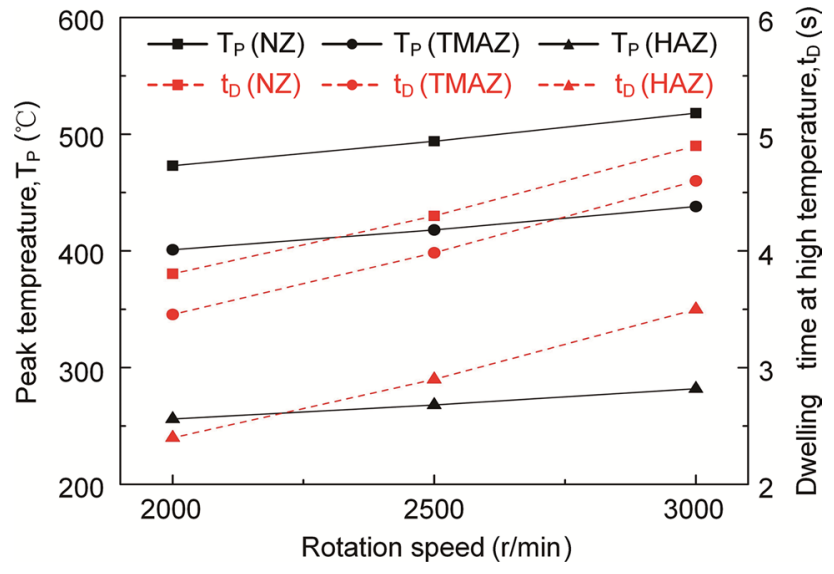

Fig. 5 Thermal characteristics involving peak temperature and dwelling time at high temperature in different zones obtained at various rotation speeds

dislocations with the BM due to no plastic deformation. When adopting the rotation speed of $2000 \mathrm{r} / \mathrm{min}$, the peak temperature $\left(256^{\circ} \mathrm{C}\right)$ was higher than the dissolution and transformation temperature of $\beta^{\prime \prime}$ precipitates, and lower than the dissolution temperature of $\beta^{\prime}$ precipitates. As a result, the $\beta^{\prime \prime}$ precipitates began to dissolve into the matrix and a part of them were transformed into $\beta^{\prime}$ precipitates. The average grain size in this zone was $38 \mu \mathrm{m}$, and the $t_{\mathrm{c}}$ of $\mathrm{Mg}$ and $\mathrm{Si}$ atoms were $5.3 \mathrm{~s}$ and $0.5 \mathrm{~s}$. When the dwelling time at high temperature was only $2.4 \mathrm{~s}, \beta^{\prime \prime}$ precipitates cannot completely dissolve into the matrix, and plenty of $\beta^{\prime \prime}$ precipitates remained in grains. Meanwhile, the transformation of $\beta$ ' $\rightarrow \beta^{\prime}$ was seriously inhibited by the fast cooling rate resulting from the high welding speed $(2000 \mathrm{~mm} / \mathrm{min})$. It can be predicted that the grains in the HAZ had lower density of $\beta^{\prime \prime}$ precipitates and slightly higher density of $\beta^{\prime}$ precipitates than that in the BM.

Figure $6 \mathrm{a}-\mathrm{c}$ shows the distribution characteristics of precipitates and dislocations, which well match with the predicted results. Additionally, PFZ coarsening was seen along the grain boundaries, and its width increased to $482 \pm 25 \mathrm{~nm}$. When raising the rotation speed to $3000 \mathrm{r} / \mathrm{min}$, the average grain size increased to $41 \mu \mathrm{m}$ and the $t_{\mathrm{c}}$ of $\mathrm{Mg}$ atoms was $6.1 \mathrm{~s}$. When the $t_{\mathrm{D}}$ was $4.1 \mathrm{~s}$, more $\beta^{\prime \prime}$ precipitates dissolved into the matrix, thus alleviating the lack of solute atoms around the grain boundaries and leading to the decrease in PFZ width. In order to verify the accuracy of the predicted results, the distributions of precipitates and dislocations of
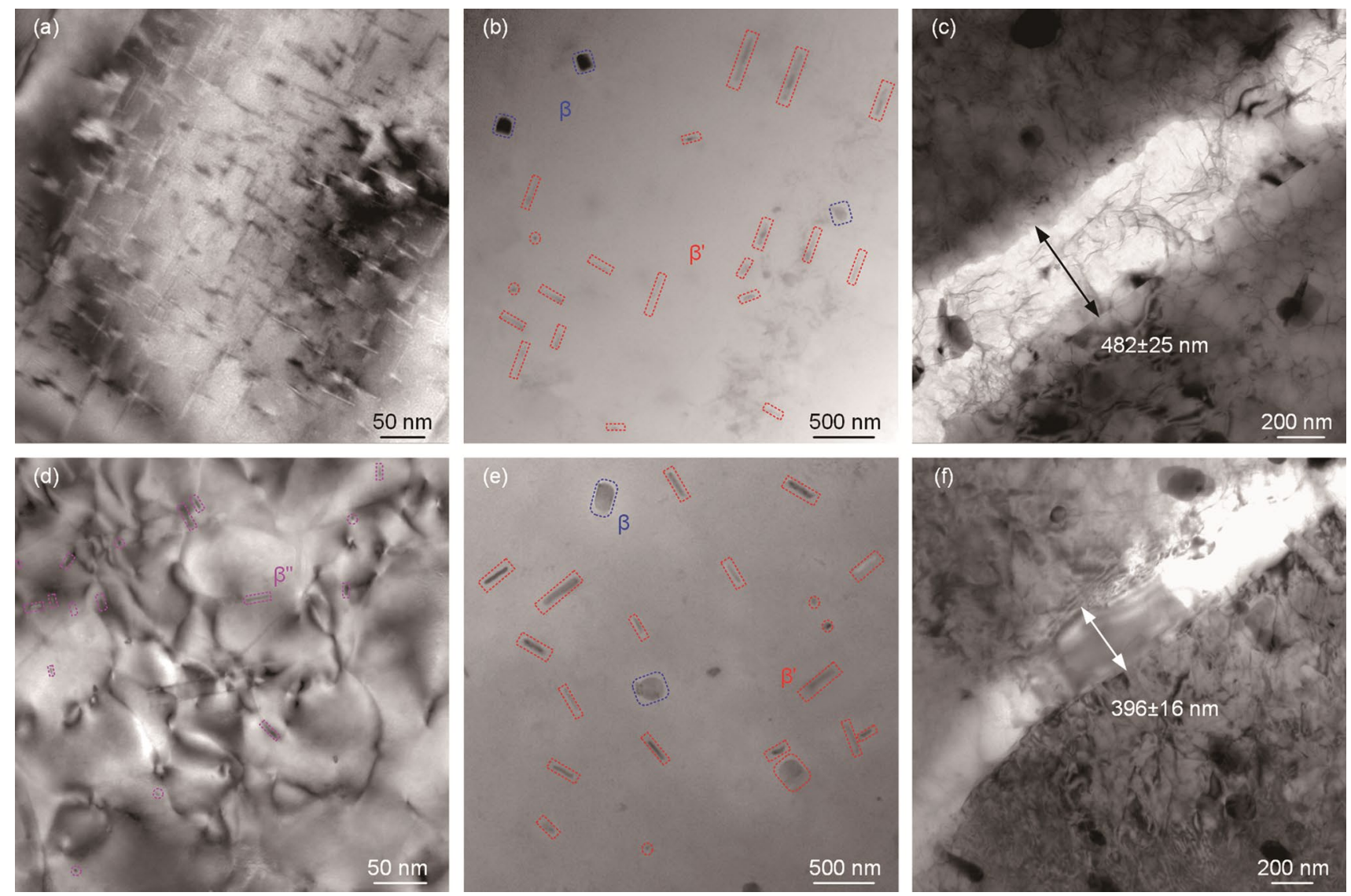

Fig. 6 TEM images showing precipitates and PFZs in the HAZs obtained at different rotation speeds: a-c $2000 \mathrm{r} / \mathrm{min}$; d-f $3000 \mathrm{r} / \mathrm{min}$ 
joint obtained at the rotation speed of $3000 \mathrm{r} / \mathrm{min}$ are shown in Fig. $6 \mathrm{~d}-\mathrm{f}$. The density of $\beta^{\prime \prime}$ precipitates truly decreased significantly, and the PFZ width decreased to $396 \pm 16 \mathrm{~nm}$. In addition, the precipitation of $\beta$ precipitates did not happen in the current temperature range, and very few $\beta$ precipitates as shown in Fig. 6 b and e were all from the BM.

Compared with the low-speed $(100-400 \mathrm{~mm} / \mathrm{min}$ ) AA6005A-T6 FSW joints in Dong et al.'s investigation [8], the dissolution and coarsening of $\beta^{\prime \prime}$ precipitates were inhibited significantly in the HAZ obtained at high welding speed $(2000 \mathrm{~mm} / \mathrm{min})$. That is to say, the HSFSW effectively shortened the dwelling time at high temperature, and weakened the precipitate coarsening and dissolution, which was useful in improving the localized softening in the microhardness.

\subsection{Microstructural Evolution in the TMAZ}

The distribution characteristics of precipitates and dislocations in the TMAZ are presented in Fig. 7. The plasticized material flow in the NZ deformed the material in the TMAZ through the viscous force, and the dislocation density exhibited an obvious increase (Fig. 7a). The peak temperature $\left(401{ }^{\circ} \mathrm{C}\right)$ in the TMAZ obtained at the rotation speed of $2000 \mathrm{r} / \mathrm{min}$ exceeded the dissolution of $\beta^{\prime}$ precipitates, leading to the precipitate evolution including the dissolution of $\beta^{\prime \prime}$ precipitates, the transformation of $\beta$ ' $\rightarrow \beta$, and the dissolution of $\beta^{\prime}$ precipitates. Very few $\beta^{\prime \prime}$ precipitates existed in grains (Fig. 7b), which indicated that the current value of $t_{\mathrm{D}}$ was low but close to the complete dissolution time of $\beta^{\prime \prime}$ precipitates.

Compared with the HAZ, the density of $\beta^{\prime}$ precipitates in the TMAZ was lower (Fig. 7c), and this implied that the amount of $\beta^{\prime}$ precipitates dissolving into the matrix was more than that coming from the transformation of $\beta^{\prime \prime}$ precipitates. The increasing dissolution degree of precipitates eliminated the PFZ. When increasing the rotation speed to $3000 \mathrm{r} / \mathrm{min}$, the heat input and "stirring force" of HSFSW tool all increased, meaning that the degree of plastic deformation and dynamic recovery increased. The increase in plastic deformation increased the dislocation density, and the increase in dynamic recovery had the opposite effect. As a consequence, the dislocation density in the TMAZ increased significantly, which demonstrated that the plastic deformation was the decisive factor affecting the dislocation density (Fig. 7d).
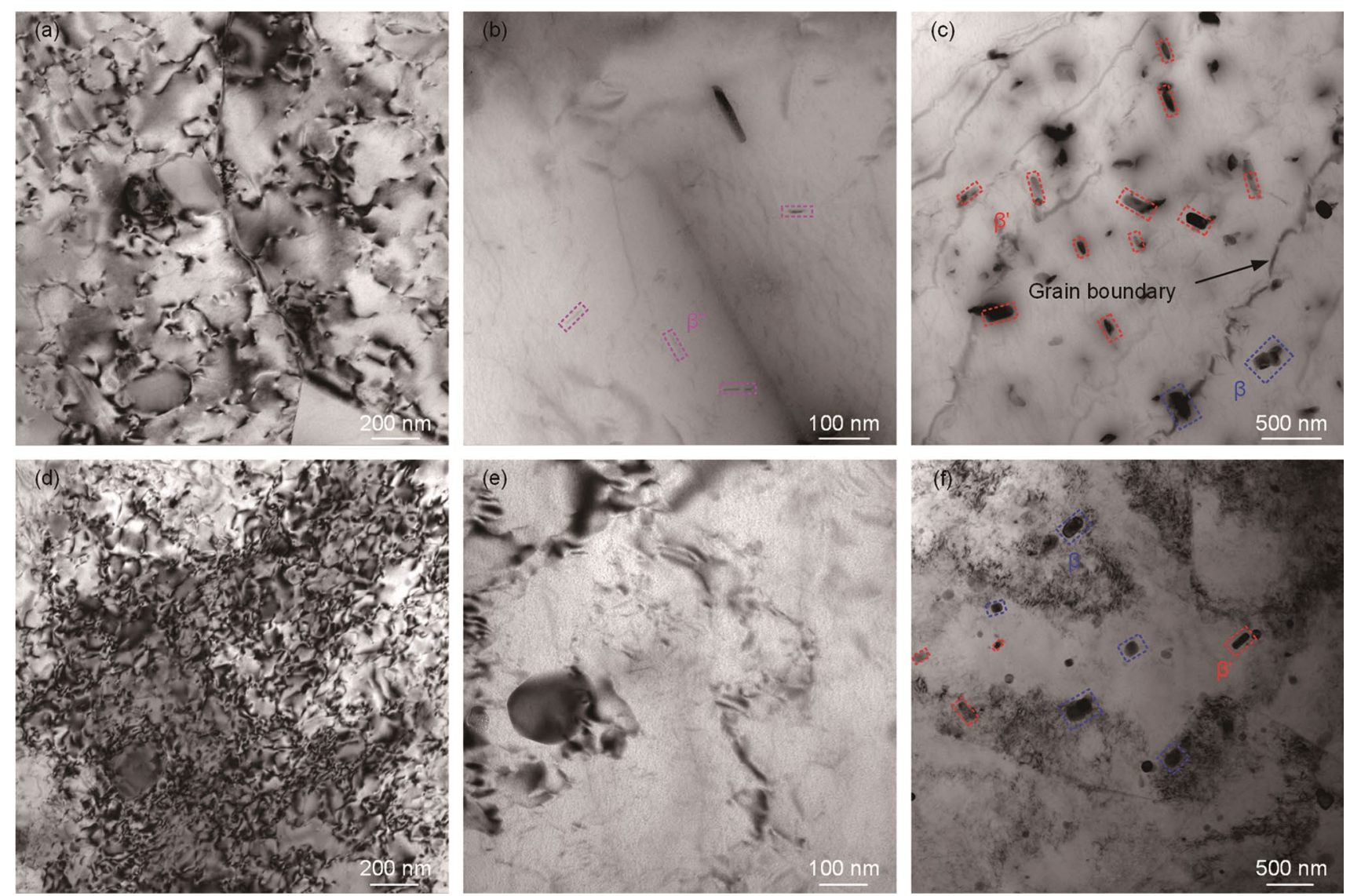

Fig. 7 TEM images showing dislocations and precipitates in the TMAZ obtained at different rotation speeds: a-c $2000 \mathrm{r} / \mathrm{min}$; d-f $3000 \mathrm{r} / \mathrm{min}$ 
The increasing heat input and dwelling time at high temperature made most of $\beta^{\prime \prime}$ precipitates dissolve into the matrix, and the others were transformed into $\beta^{\prime}$ precipitates (Fig. 7e). At the same time, parts of the transformed and original $\beta^{\prime}$ precipitates dissolved into the matrix. Additionally, very few $\beta$ precipitates, which came from the $\mathrm{BM}$, were observed in grains (Fig. 7f).

\subsection{Microstructural Evolution in the NZ}

Increasing the rotation speed increased the heat input and the grain sizes. Figure 8 gives the average grain sizes in the NZs of the HSFSW joints obtained at different rotation speeds. The average grain size was measured based on the mean linear intercept method, as shown in Fig. 9. When welding at the rotation speed of $2000 \mathrm{r} / \mathrm{min}$, the average grain size was $7.14 \mu \mathrm{m}$. At the rotation speed of $3000 \mathrm{r} / \mathrm{min}$, the average grain size increased to $9.52 \mu \mathrm{m}$.

The material in the NZ was directly stirred by the shoulder and pin, and the deformation work was stored in grains in the form of dislocations. During initial plastic deformation, dislocations were scattered randomly throughout the grains (Fig. 10a). A requirement for cell formation was that dislocations had sufficient mobility out of their slip plane, and whether cells form or not depended on the stress, the temperature, and so on $[29,30]$. The relatively high heat input and severe deformation promoted the movement of dislocations, and the dislocations clustered into a narrow region named as cell wall with a high dislocation density (Fig. 10b). Further recovery process resulted in a rearrangement of these dislocation structures into stable arrays forming dislocation walls within the individual grain itself (Fig. 10c). Then the dislocation walls gradually became thinner and sharper to form the subgrain boundaries (Fig. 10c), and each subgrain consisted of the same phase that was oriented differently in space. Based on the results of Figs. 8 and 10d, it was inferred that the original grain structure in the $\mathrm{BM}$ was eliminated and replaced by a fine equiaxed grain structure in the NZ. So, dynamic recrystallization (DRX) took place in

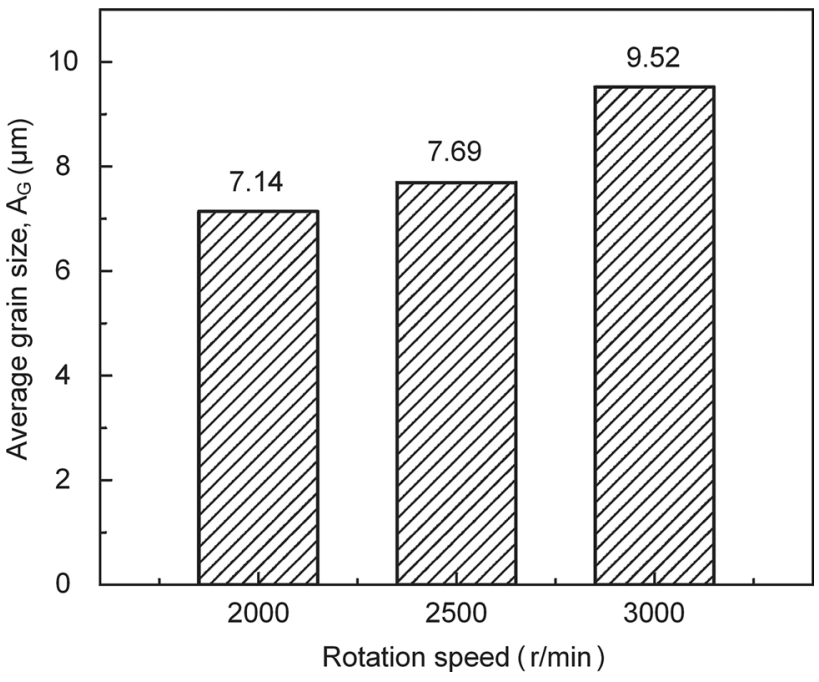

Fig. 9 Average grain sizes in the NZs of the HSFSW joints obtained at different rotation speeds

the NZ, while the TEM information on the dynamic recovery and recrystallization were both observed.

Figure 11 gives the TEM images showing dislocations and precipitates in the NZ. Woo et al. [31] measured the dislocation density using high-resolution micro-beam X-ray diffraction and found that the dynamic recrystallization in the NZ caused over $70 \%$ decrease in the dislocation density. Even though the subsequent plastic deformation introduced more dislocations, the dislocation density was still lower than that in the TMAZ (Fig. 11a). The peak temperature $\left(473{ }^{\circ} \mathrm{C}\right.$ ) in the $\mathrm{NZ}$ obtained at the $2000 \mathrm{r} / \mathrm{min}$ was higher than the dissolution temperature of $\beta^{\prime \prime}$ and $\beta^{\prime}$ precipitates, and the $t_{\mathrm{D}}(3.8 \mathrm{~s})$ was larger than the $t_{\mathrm{c}}$ of $\mathrm{Mg}$ atom $(2.2 \mathrm{~s})$. So, all the strengthening precipitates dissolved into the matrix, and a low density of $\beta^{\prime}$ precipitates were transformed into $\beta$ precipitates (Fig. 11b). When increasing the rotation speed, the density of dislocations and the amount of $\beta$ precipitates coming from the transformation of $\beta^{\prime}$ precipitates increased to some extent (Fig. 11c, d).
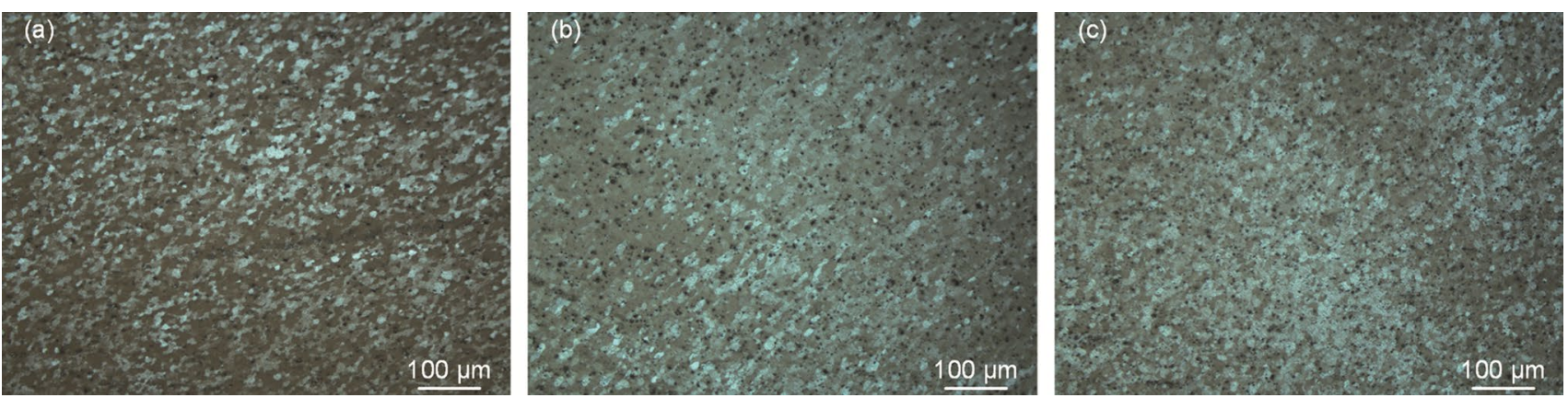

Fig. 8 Optical pictures showing grain structures in the NZs obtained at different rotation speeds: a $2000 \mathrm{rpm}$, b $2500 \mathrm{rpm}$, c $3000 \mathrm{rpm}$ 

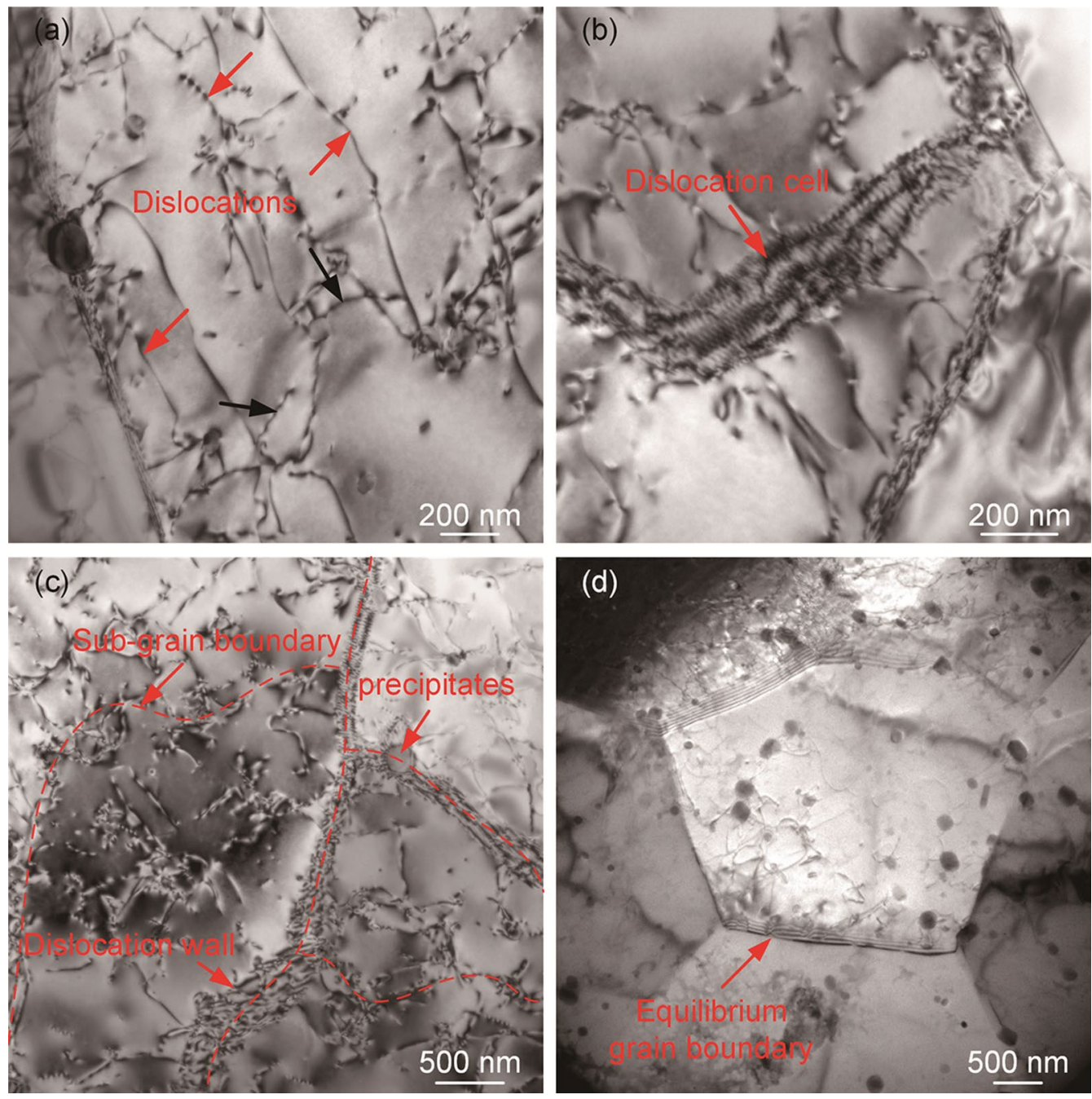

Fig. 10 Dislocation structures in the NZ: a dislocation multiplication, $\mathbf{b}$ dislocation cells, $\mathbf{c}$ subgrain boundaries and dislocation walls, $\mathbf{d}$ grain boundaries

\subsection{Relationship Between Microstructures and Microhardness}

Figure 12 gives the relationship between microstructure characteristics and microhardness distribution of the HSFSW joint (2000 r/min, $2000 \mathrm{~mm} / \mathrm{min}, 21 \mathrm{kN})$. After solid solution and artificial aging, a high density of $\beta^{\prime \prime}$ precipitates and a low density of $\beta^{\prime}$ precipitates were distributed homogeneously in the grains of BM (I zone), and the zone showed the highest microhardness. The dislocation density in the HAZ (II and III zones) stayed the same with the BM because of no plastic deformation and fine-grain strengthening. A part of $\beta^{\prime \prime}$ precipitates cannot dissolve into the matrix in a short time, and contributed to the microhardness in a way of precipitation strengthening. The difference between the HAZ close to BM (II zone) and the HAZ close to TMAZ (III zone) was the coarsening and dissolution degree of $\beta^{\prime \prime}$ precipitate. The lowest microhardness was usually located in the III zone. In the TMAZ (IV zone), the effect of dislocation strengthening was stronger than that in other zones because of the highest dislocation density, and solid solution strengthening worked resulting from the $\beta^{\prime}$ precipitates. The effects of solid solution and fine-grain strengthening in the NZ (V zone) were the strongest due to the full dissolution of strengthening precipitates and the recrystallized grains. In addition, the dislocation strengthening effect was also strong because of a high density of dislocations. As a consequence, the microhardness in the NZ was higher than in other softened zones. The above description is summarized in Table 1.

The effect of rotation speed on the changes in strengthening mechanisms in different zones of HSFSW joints is demonstrated in Table 2. With the increase in rotation speed, the values of $T_{\mathrm{P}}$ and $t_{\mathrm{D}}$ all increased. In the HAZ, the precipitation strengthening effect was weakened, and the solid solution strengthening effect was improved. 

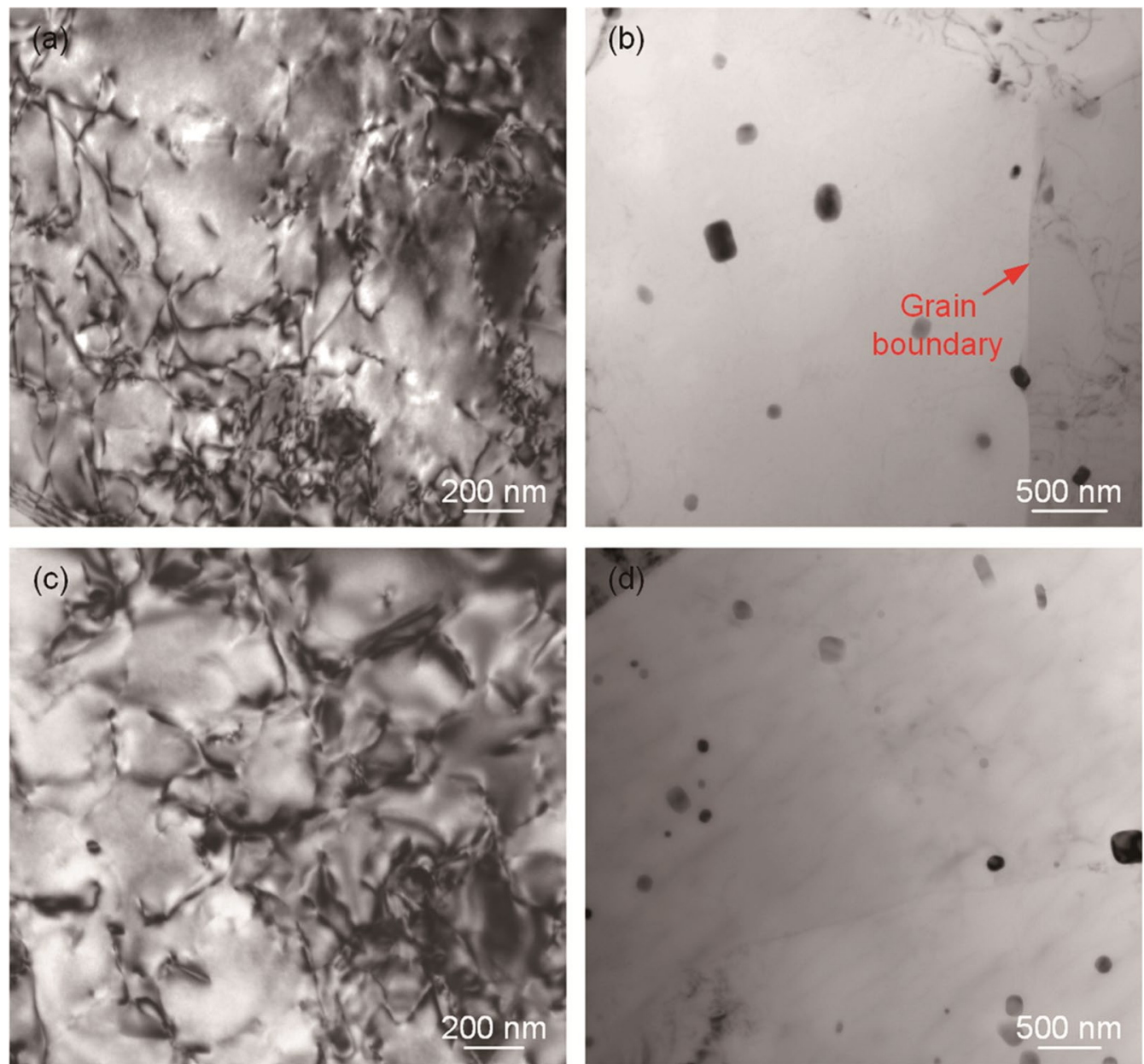

Fig. 11 TEM images showing dislocations and precipitates in the NZs obtained at different rotation speeds: a-b 2000 r/min; c-d 3000 r/min
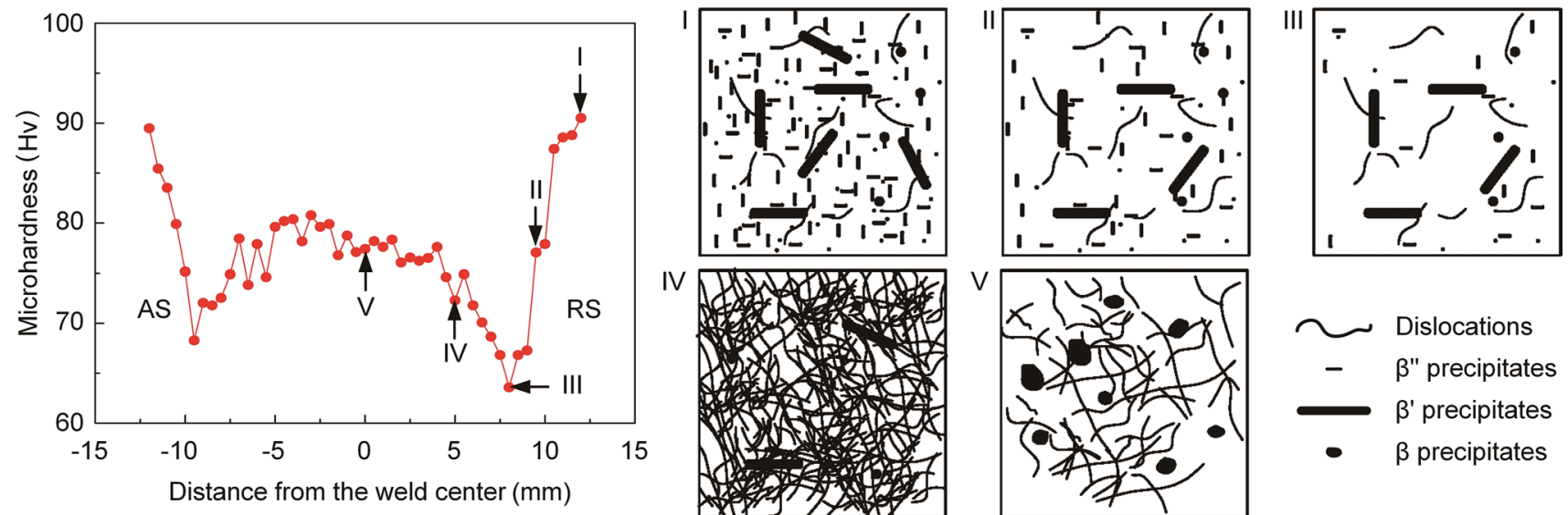

Fig. 12 Relationship between microhardness distribution and microstructure characteristics

The microhardness finally depended on the comprehensive function of these two strengthening effects. In the TMAZ, the increasing dislocation density increased the dislocation strengthening effect, while the increasing precipitation dissolution decreased the precipitation strengthening effect. In the NZ, the fine-grain strengthening effect 
Table 1 Relationship between microstructure characteristics and microhardness

\begin{tabular}{llllll}
\hline Zone & \multicolumn{2}{l}{ Strengthening mechanism } & & Microhardness \\
\cline { 2 - 4 } & Precipitation & Solid solution & Dislocation & Fine-grain & \\
\hline BM (I) & Strongest & Weakest & Weak & - & Highest \\
HAZ (II) & Stronger & Weaker & Weak & - & Higher \\
HAZ (III) & Weaker & Weaker & Weak & - & Lowest \\
TMAZ (IV) & Weakest & Stronger & Strongest & - & Lower \\
NZ (V) & - & Strongest & Stronger & Strongest & High \\
\hline
\end{tabular}

Table 2 Effect of rotation speed on the changing trends of strengthening mechanisms in different zones

\begin{tabular}{lllll}
\hline $\begin{array}{l}\text { Rotation } \\
\text { speed } \uparrow\end{array}$ & \multicolumn{2}{l}{ Strengthening mechanism } & \\
\cline { 2 - 5 } & Precipitation & $\begin{array}{l}\text { Solid solu- } \\
\text { tion }\end{array}$ & Dislocation & Fine-grain \\
\hline HAZ & $\downarrow$ & $\uparrow$ & Same & None \\
TMAZ & $\downarrow$ & Small up & $\uparrow$ & None \\
NZ & None & Small up & $\uparrow$ & $\downarrow$ \\
\hline
\end{tabular}

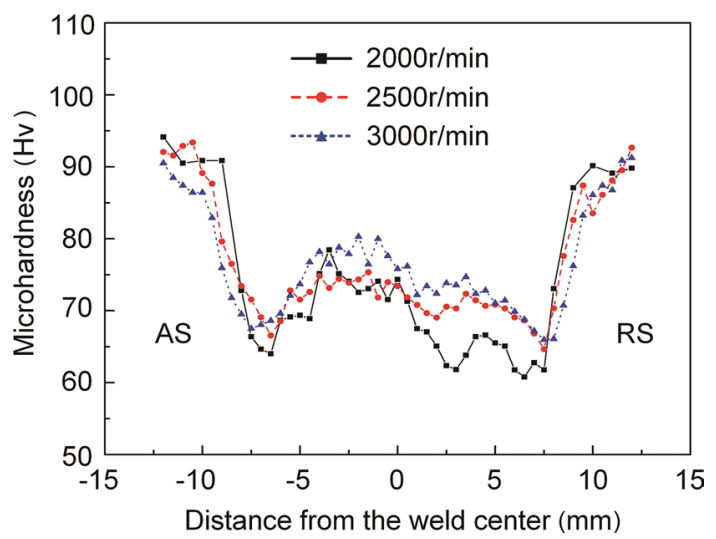

Fig. 13 Microhardness distribution of the HSFSW joints obtained at different rotation speeds

was weakened because of grain coarsening. Meanwhile, the dislocation strengthening effect was elevated by the increase in dislocation density. As a result, the microhardness distributions of the welded joints obtained at different rotation speeds are shown in Fig. 13. When increasing the rotation speed from 2000 to $3000 \mathrm{r} / \mathrm{min}$, both the width and microhardness value of the softened zone increased. The results demonstrated that the solid solution strengthening played theleading role in the HAZ, and the dislocation strengthening played the leading role in the TMAZ and NZ.

All in all, the microhardness distribution depended on microstructural characteristics including grains, dislocations, and precipitates. Correspondingly, the microhardness evolution was the reflection of microstructure changes.

\section{Conclusions}

In this study, the joints for high-speed friction stir welding of AA6005A-T6 aluminum hollow extrusions were obtained at different rotation speeds. The relationship between microstructures and microhardness was investigated. The main conclusions were drawn as follows.

(1) The BM contained a high density of $\beta^{\prime \prime}$ precipitates and a low density of $\beta^{\prime}$ precipitates. In the HAZ, a part of $\beta^{\prime \prime}$ precipitates dissolved into the matrix, and the density of $\beta^{\prime}$ precipitates was hardly changed.

(2) The $\beta^{\prime \prime}$ precipitates completely dissolved into the matrix, and a low density of $\beta^{\prime}$ precipitates were observed in the TMAZ. Meanwhile, this zone had the highest density of dislocations.

(3) Dynamic recrystallization (DRX) occurred in the NZ, which was characterized by fine equiaxed grains. The $\beta^{\prime \prime}$ precipitates and most of the $\beta^{\prime}$ precipitates dissolved into the matrix, and a few $\beta^{\prime}$ precipitates were transformed into the $\beta$ precipitates.

(4) The lowest microhardness was located in the HAZ close to the TMAZ as for the HSFSW joint, and the microhardness in the NZ was higher than in other softened zones. When increasing the rotation speed, the microhardness in different zones increased in different degrees.

Acknowledgements This work was supported by the National Natural Science Foundation of China (Nos. 51435004, 51175117, U1404502) and the National Science and Technology Major Project of China (No. 2010ZX04007-011).

\section{References}

[1] X. Lu, C.S. Zhang, G.Q. Zhao, Y.J. Guan, L. Chen, A.J. Gao, Mater. Design 89, 737 (2016)

[2] T. Kawasaki, T. Makino, K. Masai, H. Ohba, Y. Ina, E. Masakuni, JSME Int. J. 47, 502 (2004)

[3] G. Liu, L.N. Ma, Z.D. Ma, X.S. Fu, G.B. Wei, Y. Yang, T.C. Xu, W.D. Xie, X.D. Peng, Acta Metall. Sin. (Engl. Lett.) 31, 853 (2018) 
[4] G.K. Padhy, C.S. Wu, S. Gao, J. Mater. Sci. Technol. 34, 1 (2018)

[5] A. Alessandro, J. Carstensen, J.F. dos Santos, J. Mater. Sci. Technol. 34, 119 (2018)

[6] J.W. Qian, J.L. Li, F. Sun, J.T. Xiong, F.S. Zhang, X. Lin, Scr. Mater. 68, 175 (2013)

[7] V. Dixit, R.S. Mishra, R.J. Lederich, R. Talwar, Sci. Technol. Weld. Join. 12, 334 (2007)

[8] P. Dong, H.M. Li, D.Q. Sun, W.B. Gong, J. Liu, Mater. Design 45, $524(2013)$

[9] Z. Zhang, B.L. Xiao, Z.Y. Ma, Mater. Charact. 106, 255 (2015)

[10] S. Malopheyev, I. Vysotskiy, V. Kulitskiy, S. Mironov, R. Kaibyshev, Mater. Sci. Eng. A 662, 136 (2016)

[11] A.H. Feng, D.L. Chen, Z.Y. Ma, W.Y. Ma, R.J. Song, Acta Metall. Sin. (Engl. Lett.) 27, 723 (2014)

[12] D. Rao, K. Huber, J. Heerens, J.F. dos Santos, N. Huber, Mater. Sci. Eng. A 565, 44 (2013)

[13] H.J. Liu, X.Q. Liu, X.G. Wang, T.H. Wang, S. Yang, Int. J. Adv. Manuf. Technol. 88, 3139 (2017)

[14] X.Q. Liu, H.J. Liu, T.H. Wang, X.G. Wang, S. Yang, J. Mater. Sci. Technol. 34, 102 (2018)

[15] C.Y. Liu, B. Qu, P. Xue, Z.Y. Ma, K. Luo, M.Z. Ma, R.P. Liu, J. Mater. Sci. Technol. 34, 112 (2018)

[16] S.J. Andersen, H.W. Zandbergen, J. Jansen, C. Træholt, U. Tundal, O. Reiso, Acta Mater. 46, 3283 (1998)

[17] R. Vissers, M.A. van Huis, J. Jansen, H.W. Zandbergen, C.D. Marioara, S.J. Andersen, Acta Mater. 55, 3815 (2007)
[18] M.H. Jacobs, Philos. Mag. A 26, 1 (1972)

[19] Y.S. Sato, M. Urata, H. Kokawa, Metall. Mater. Trans. A 33, 625 (2002)

[20] W.C. Yang, L.P. Huang, R.R. Zhang, M.P. Wang, Z. Li, Y.L. Jia, R.S. Lei, X.F. Sheng, J. Alloys Compd. 514, 220 (2012)

[21] Y. Wang, Z.K. Liu, L.Q. Chen, C. Wolverton, Acta Mater. 55, 5934 (2007)

[22] K. Matsuda, Y. Sakaguchi, Y. Miyata, Y. Uetani, T. Sato, A. Kamio, S. Ikeno, J. Mater. Sci. 35, 179 (2000)

[23] G.A. Edwards, K. Stiller, G.L. Dunlop, M.J. Couper, Acta Mater. 46, 3893 (1998)

[24] A. Gaber, A.M. Ali, K. Matsuda, T. Kawabata, T. Yamazaki, S. Ikeno, J. Alloys Compd. 432, 149 (2007)

[25] Y. Li, L.E. Murr, J.C. McClure, Mater. Sci. Eng. A 271, 213 (1999)

[26] C. Gallais, A. Denquin, Y. Bréchet, G. Lapasset, Mater. Sci. Eng. A 496, 77 (2008)

[27] E.F. AboZeid, A. Gaber, Mater. Sci. Technol. 27, 487 (2011)

[28] P. Dong, Doctoral dissertation, Jilin University, 2014

[29] D.L. Holt, J. Appl. Phys. 41, 3197 (1970)

[30] H. Mughrabi, Acta Mater. 31, 1367 (1983)

[31] W. Woo, L. Balogh, T. Ungár, H. Choo, Z.L. Feng, Mater. Sci. Eng. A 498, 308 (2008) 